\title{
Immunotherapy: a 10-year anniversary issue
}

\author{
Mike Gregg*,1 \\ ${ }^{1}$ Future Science Group, Unitec House, 2 Albert Place, London N31QB, UK \\ *Author for correspondence: m.gregg@futuremedicine.com
}

\begin{abstract}
"Although the past decade has provided many significant discoveries across all specialties in immunotherapy, we hope the coming decade will provide many further opportunities to advance our understanding and develop more effective diagnostic methods and treatments."”
\end{abstract}

\section{Keywords: allergies $\bullet$ antibodies $\bullet$ autoimmune diseases $\bullet$ immunotherapy $\bullet$ obesity $\bullet$ vaccines}

In the 10 years since our launch, this diverse field has evolved dramatically and Immunotherapy has strived to present and highlight all the latest advances across the whole research spectrum. This exciting decade for the field has seen remarkable developments in the applications of immunotherapy which has led to a range of new treatments for autoimmune diseases, allergies and cancer. In particular, the emergence and advancement in the study and application of genetically engineered chimeric antigen receptor T cells (CAR-T cells) and checkpoint inhibitors for the treatment of cancer have been key areas of research in recent years.

This special decennial anniversary issue celebrates 10 years since the launch of Immunotherapy. Compiled with the help of members of the journal's editorial board and regular contributors, this issue includes a variety of short editorials, commentaries, reviews and research articles. It aims to provide a broad representation of the progress made in particular areas of immunotherapy, detailing the past, present and future possibilities in the diagnosis and treatment of cancers, allergies and autoimmune diseases.

In an editorial by Francesco Panza et al. [1], the authors discuss the potential of using antibodies against amyloid$\beta$ (A- $\beta$ ) oligomers in order to prevent Alzheimer's disease. This article covers the past and present situation of treatment in this area and proposes future strategies to improve healthcare for patients with Alzheimer's disease.

The article by Amadou Barry and colleagues [2] looks at the importance of being scientifically cautious when criticizing the administration of vaccines. Their editorial provides an insight into the dangers caused when false conclusions are made on vaccinations due to incorrect information being spread to the public.

An interesting article by Ziming Wang et al. [3] focuses on the complex effects that obesity has on cancer and immunotherapy. While the majority of cancer research focuses on the cancer itself for successful treatment, it is also important to have a deep understanding of the immune status of the patient. This study looks at how obesity and the age of a patient can actually promote cancer progression and how it is important to personalize treatment dependent on these factors.

The commentary by Ariana Renrick and colleagues [4] provides an important update on the range of cancer immunotherapies that are on trial or presently available to patients. It provides a summary of each type of treatment and discusses the potential they have in treating cancer.

An interesting research article by Melissa Bersanelli et al. [5] looks at how the immune context of renal cell carcinoma can be useful in predicting the benefits from immunotherapy.

The special report written by Jun Liu et al [6], entitled 'Use of CAR-T cells in allogeneic hematopoietic stem cell transplantation', provides direction on the most effective use of CAR-T cells in patients with allogeneic hematopoietic stem cell transplantation (allo-HSCT).

The final article in this issue is a review written from Katarzyna Wlodarek et al. [7] entitled 'Biologics for hidradenitis suppurativa: an update. This piece provides an in-depth overview of the treatments, both old and new, hidradenitis suppurativa, a rare chronic skin condition.

Although the past decade has provided many significant discoveries across all specialties in immunotherapy, we hope the coming decade will provide many further opportunities to advance our understanding and develop more effective diagnostic methods and treatments. The Immunotherapy Editorial Department would like to take this 
opportunity to thank all readers, authors, editorial board members and other contributors for the past 10 years and we look forward with excitement to the next decade.

\section{Financial \& competing interests disclosure}

The author is an employee of Future Science Group. The author has no other relevant affiliations or financial involvement with any organization or entity with a financial interest in or financial conflict with the subject matter or materials discussed in the manuscript apart from those disclosed.

No writing assistance was utilized in the production of this manuscript.

\section{References}

1. Panza F, Lozupone M, Dibello V et al. Are antibodies directed against amyloid- $\beta$ ( $A \beta$ ) oligomers the last call for the $A \beta$ hypothesis of Alzheimer's disease? Immunotherapy 11(1), 3-6 (2019).

2. Barry A, Bottasso OA, Vicco MH. The importance of being scientifically cautious when criticizing the administration of vaccines. Immunotherapy 11(1), 7-9 (2019).

3. Wang Z, Monjazeb AM, Murphy WJ. The complicated effects of obesity on cancer and immunotherapy. Immunotherapy 11(1), 11-14 (2019).

4. Renrick AN, Dunbar ZT, Shanker A. Update on the current revolution in cancer immunotherapy. Immunotherapy 11(1), 15-20 (2019).

5. Bersanelli M, Gnetti L, Varotti $\mathrm{E}$ et al. Immune context characterization and heterogeneity in primary tumors and pulmonary metastases from renal cell carcinoma. Immunotherapy 11(1), 21-35 (2019).

6. Liu J, Zhang X, Zhong JF, Zhang C. Use of chimeric antigen receptor T cells in allogeneic hematopoietic stem cell transplantation. Immunotherapy 11(1), 37-44 (2019).

7. Włodarek K, Ponikowska M, Matusiak L, Szepietowski JC. Biologics for hidradenitis suppurativa: an update. Immunotherapy 11(1), 45-59 (2019). 